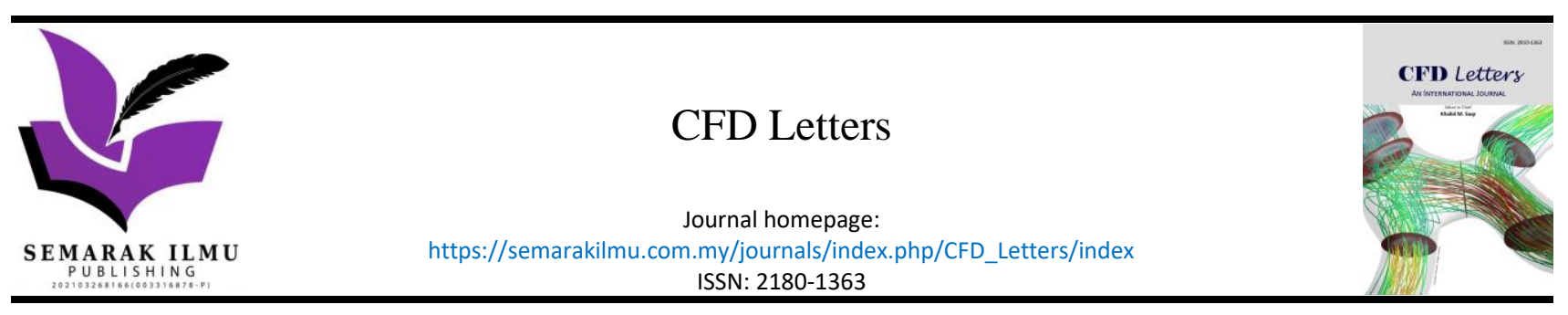

\title{
Predictive Numerical Analysis to Optimize Ventilation Performance in a Hydropower Surge Chamber for $\mathrm{H}_{2} \mathrm{~S}$ Removal
}

\author{
Mohammad Nurizat Rahman ${ }^{1, *}$, Mohd Shiraz Aris ${ }^{1}$, Mohd Haffis Ujir ${ }^{2}$, Mohd Hariffin Boosroh ${ }^{3}$, \\ Dinishkaran Pillai a/I Velayutham Pillai ${ }^{4}$
}

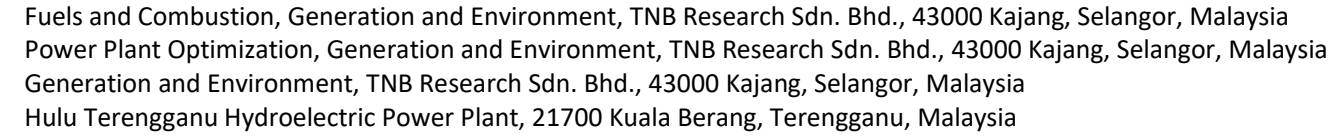

\section{ARTICLE INFO}

\section{Article history:}

Received 24 August 2021

Received in revised form 8 September 2021

Accepted 9 September 2021

Available online 31 October 2021

\section{Keywords:}

Computational Fluid Dynamics (CFD); indoor air pollution; ventilation; hydropower surge chamber; $\mathrm{H}_{2} \mathrm{~S}$ removal

\section{ABSTRACT}

The role of a hydropower plant surge chamber as a pressure buffer to compensate excessive pressure fluctuations as a result of load demand variations contributes to the degassing phenomenon of hydrogen sulfide $\left(\mathrm{H}_{2} \mathrm{~S}\right)$. Recent data collected from the surge chamber of a hydropower plant reveals that the $\mathrm{H}_{2} \mathrm{~S}$ extraction designs are not effective in controlling the $\mathrm{H}_{2} \mathrm{~S}$ concentration levels especially during surge events. To manage a safe working environment in the presence of $\mathrm{H}_{2} \mathrm{~S}$ requires a systematic evaluation and prediction of the influence of critical flow control conditions in relation to suction optimization and exhaust ducting location. A numerical study was carried out to analyze the flow dynamics and the subsequent response of $\mathrm{H}_{2} \mathrm{~S}$ concentrations to cases involving the following flow mixing and suction scenarios: $\mathrm{C} 1$ - absence of suction fans, C2 - absence of fresh air supply, C3 - enhanced suction capability, C4 reduction in the amount of fresh air supply and C5 - presence of additional ducting. The CFD model was able to provide a reliable assessment of the case scenarios as justified by the validation carried out with in-situ measurements (within $10 \%$ of the actual measured data). The cases where the $\mathrm{H}_{2} \mathrm{~S}$ presence was found to be acceptable with concentrations less than $5 \mathrm{ppm}$ at the upper region of the surge chamber, are C3, C4 and C5. A major finding from the flow studies in the surge chamber is that a combination of negative pressure at the suction locations and the absence of the forced fresh air resulted in significant amount of air drawn in from the outdoors. It was also found that the existing forced fresh air inlet locations are inappropriate as they generate vortex flows which displaces the $\mathrm{H}_{2} \mathrm{~S}$ adjacent to the water level upwards and would later fill the entire chamber. All in all, the validated CFD model of the hydropower plant surge chamber was helpful in providing an understanding of the flow conditions in relation to the management of $\mathrm{H}_{2} \mathrm{~S}$ concentrations.

\section{Introduction}

Hydroelectric power stations typically operate on a base-load mode with the occasional requirement to meet sudden large load demands (spikes). In the event of load spikes, the hydro plant

\footnotetext{
* Corresponding author.

E-mail address: izatfariz49@gmail.com (Mohammad Nurizat Rahman)
} 
will be subjected to surge events whereby the amount of water flowing into the turbines will drastically increase. As the water body experiences fluctuating velocities due to the flowrate variability, coupled with the compressibility and elasticity of the piping material, the water hammering phenomenon will most likely occur. A surge chamber is a feature put in place to overcome the impact of water hammer whereby the surge chamber reservoir acts as a pressure buffer for the connected piping system [1,2]. Figure 1 illustrates the surge chamber location in relation to the major components of a hydropower plant. As the water leaves the dam outlet, the high pressure water is directed to the hydro turbines through a closed conduit (penstock) and will continue to the surge chamber before rejoining the main flow out of the hydropower plant.

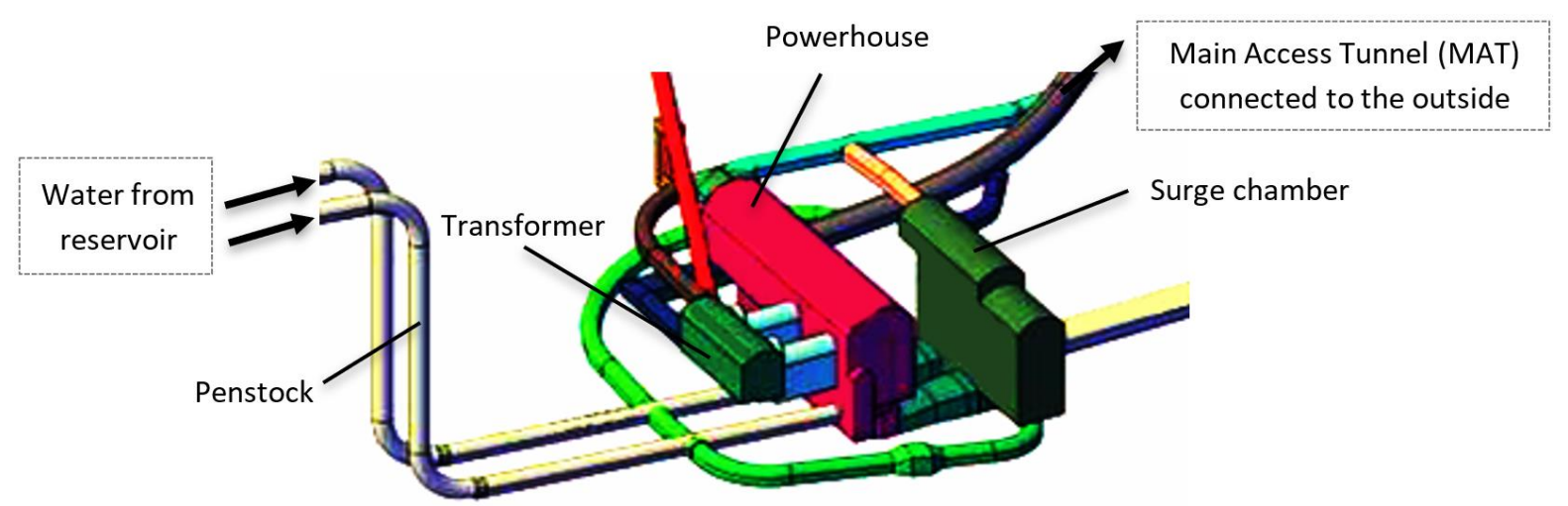

Fig. 1. Example of an underground surge chamber and other components in a hydropower plant [3]

While the surge chamber addresses the impact of water hammer, there is a significant side effect of the chamber design and water chemistry to the operation of hydropower plants. Due to the bacterial activities associated to organic decay in the hydro dams and water sources, it is common to find high concentrations of hydrogen sulfide $\left(\mathrm{H}_{2} \mathrm{~S}\right)$ within the surge chamber air space. The presence of $\mathrm{H}_{2} \mathrm{~S}$, at concentrations above $5 \mathrm{ppm}$ is already a Health, Safety and Environment (HSE) risk which the plant operators will have to manage and continuous exposure will also result in equipment failure as corrosion attacks the metallic components in the gas flow path [4]. Hence, $\mathrm{H}_{2} \mathrm{~S}$ degassing can be regarded as a waste that must be eliminated or reduced to the minimal [5].

The mechanism of $\mathrm{H}_{2} \mathrm{~S}$ migration from the water body to the surrounding air space is best described by the degassing phenomena of the dissolved concentration to a liberated state via mechanical intervention i.e., mixing. Degassing in the surge chamber is linked to the gush of water entering the surge chamber reservoir during surge events [6]. The turbulence and intensified mixing at the water surface amplifies the degassing process and result in more $\mathrm{H}_{2} \mathrm{~S}$ entering the surrounding air space. The gaseous $\mathrm{H}_{2} \mathrm{~S}$ concentration will remain at a space adjacent to the water level due to its higher density compared to air. The possibility of the subsequent spread of $\mathrm{H}_{2} \mathrm{~S}$ to other sections of the surge chamber is driven by the air movements and pressure difference in the surrounding air space. The water levels which rise during surge events will also contribute to the impact of $\mathrm{H}_{2} \mathrm{~S}$ to its surroundings as the exposure is closer to critical areas of equipment and human life. Figure 2 illustrates a cross section of the surge chamber showing the respective water levels during high and low-demand hours. 


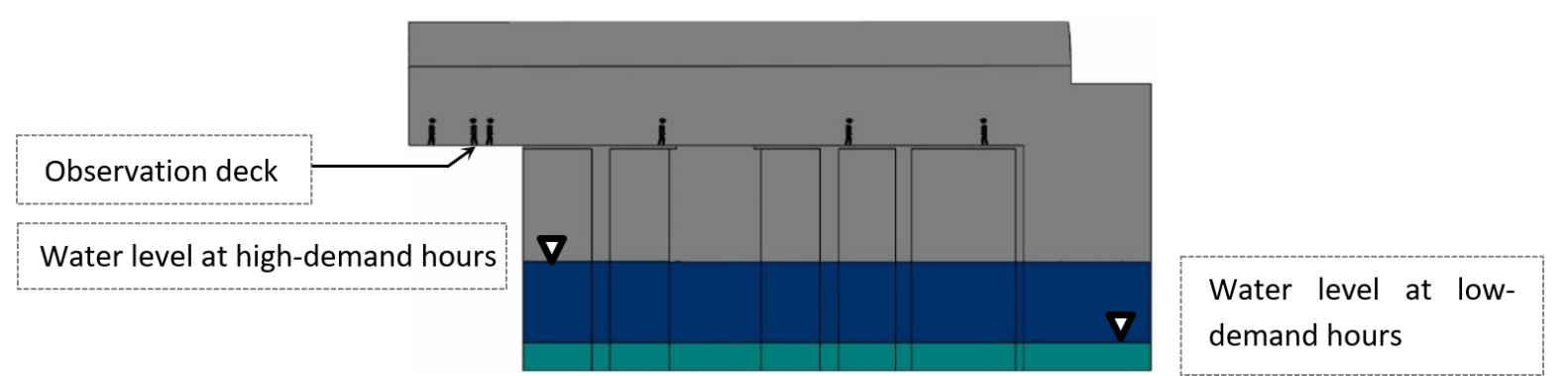

Fig. 2. Cross section of the surge chamber and reservoir water level during low-demand hours (normal operation) and high-demand hours

One of the typical mitigation measures taken to manage the $\mathrm{H}_{2} \mathrm{~S}$ spread is through the use of forced air vents. Unfortunately, with the flow of fresh air from other locations entering the chamber, including the main door opening, the $\mathrm{H}_{2} \mathrm{~S}$ concentration is often displaced and spread throughout the building air space, making extraction a difficult task. The risk of $\mathrm{H}_{2} \mathrm{~S}$ exposure will not be solved unless more insights on the flow movements and air space conditions are well understood.

A numerical analysis using a Computational Fluid Dynamics (CFD) package will enable the optimization of $\mathrm{H}_{2} \mathrm{~S}$ control methods via fresh air input, extraction designs or a combination of the two. There are numerous past studies that have successfully used numerical analysis to optimize ventilation solutions in confined spaces and underground constructions i.e., sub-way and metro tunnels, underground works, road tunnel, mines, under-ground shelters, underground storage and underground park structures [7-15]. The present study explored the use of CFD to analyze flow patterns for a hydropower plant surge chamber in normal and several high risk operational conditions. The CFD modelling involved a physical and numerical set-up phase to identify the calculation domain, physical attributes and the relevant hydrodynamic equations which best represents the flow conditions.

\section{Physical Setup}

The three-dimensional (3D) geometry of a hydropower plant surge chamber was developed in this study using as-built dimensions obtained from the power plant. The surge chamber geometry was simplified to capture important features and the non-critical components were intentionally leftout in the interest of computational time and cost. To account for the degassing of $\mathrm{H}_{2} \mathrm{~S}$ from the water surface, actual concentration measurements were taken at several locations above the reservoir water level and introduced as boundary conditions for the CFD model. Figure 3 shows the computing domain of the modelled surge chamber and the respective boundary condition locations including two regions of turbulence and calm water. 


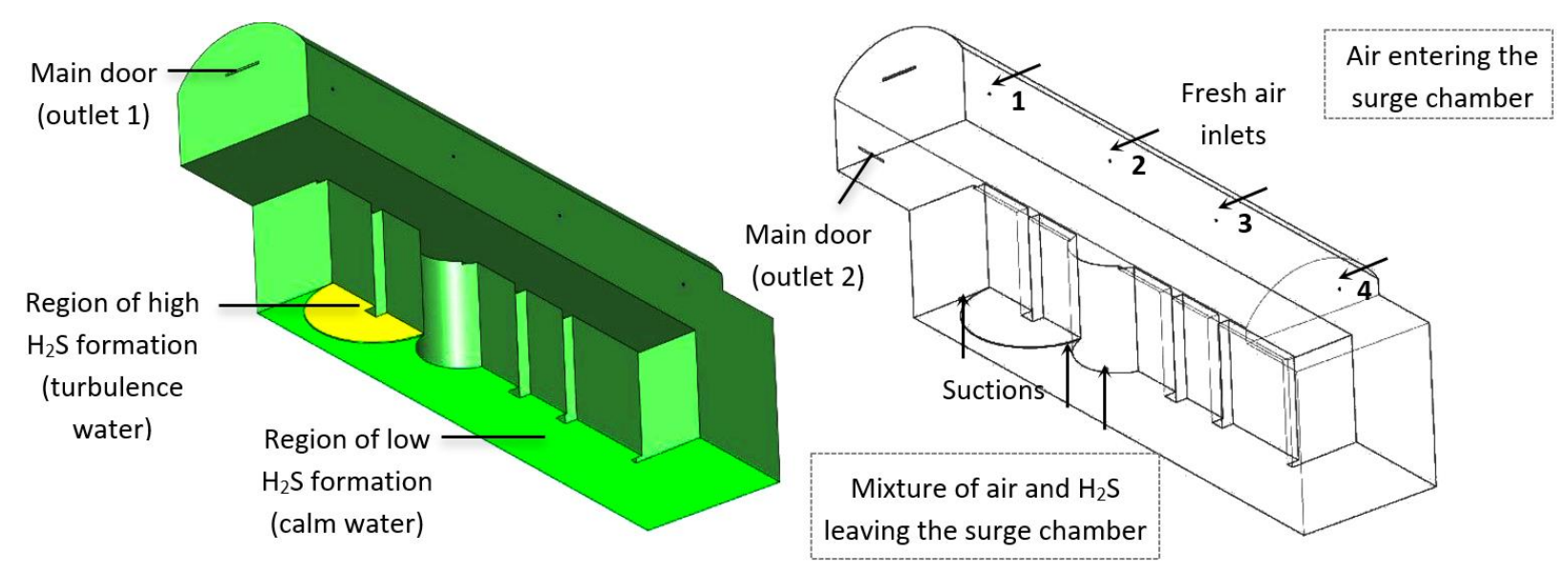

(a)

(b)

Fig. 3. The computing domain of the modelled surge chamber showing (a) external and (b) internal configurations with the respective boundary condition locations

In simulating the air and $\mathrm{H}_{2} \mathrm{~S}$ concentrations in the surge chamber air space, a few operational conditions were considered. Fresh air was allowed to enter the surge chamber air space through two main door outlets (natural ventilation) and four fresh air inlets (forced ventilation). The reservoir water body was not considered to be part of the computed domain to simplify the analysis.

\section{Numerical Setup}

The finite volume method which is the basis of the mathematical technique used in the CFD package divides the computing domain of the surge chamber into smaller control volumes (mesh volumes). The governing equations are converted into discrete forms using a commercial CFD software package, ANSYS Fluent V.19 R1. ANSYS Fluent V.19 R1 is used for all setups and numerical processing. The ANSYS Fluent solver is widely used for ventilation simulations, and these simulation approaches have been thoroughly validated [16]. As a result, this is a viable method for simulating gases dispersion-related phenomena. The pressure-based solver is utilized to resolve the governing equations. To solve the pressure-velocity coupling, the coupled method was chosen. The coupled algorithm solves both conservation of mass and momentum simultaneously thus permitting the interdependencies of these equations. Since the pressure-based method is used in the present contribution, the first law of thermodynamics for the conservation of energy will be solved sequentially.

The Shear Stress Transport (SST) $k-\omega$ model is employed to resolve the turbulence behavior. In the SST $k-\omega$ model, the steady Reynolds-averaged Navier-Stokes (RANS) equations are obtained by splitting the instantaneous flow variables into fluctuating and steady components and applying Reynolds averaging techniques to the Navier-Stokes (NS) equations. Following the Reynolds averaging technique, new terms called Reynold stresses appear, which represent the turbulence effects. Reynolds stresses are resolved via the Boussinesq hypothesis to link the Reynolds stresses to the mean velocity gradients in order to close the RANS equations. The term turbulence viscosity emerges from this relation. To resolve turbulent viscosity, the SST $k-\omega$ model is used. Hence, in the SST $k-\omega$ model, turbulent viscosity is calculated as a function of turbulence kinetic energy, $k$ and specific dissipation rate, $\omega$. Menter $[17,18]$ provided detail information on the constants and formulations used in the SST $k-\omega$ model. The use of RANS simulations has been shown to produce results that are consistent with the gases dispersion experimental data [16]. 
The validated baseline case was built using actual power plant operating conditions. Subsequently, the following flow mixing and suction scenarios were modeled: $\mathrm{C} 1$ - absence of suction fans, C2 - absence of fresh air supply, C3 - enhanced suction capabilities, C4 - reduction in the amount of fresh air supply, and C5 - presence of extra ducting. All simulations were done on 6 central processing unit (CPU) processors for a total CPU time of 243 hours. Table 1 shows the corresponding boundary conditions for each case.

Table 1

Velocity for each boundary

\begin{tabular}{|c|c|c|c|c|c|c|}
\hline \multirow[t]{2}{*}{ Boundaries } & \multicolumn{6}{|l|}{ Case studies } \\
\hline & Baseline & $\mathrm{C} 2$ & $\mathrm{C} 3$ & $\mathrm{C} 4$ & $\mathrm{C} 5$ & $\mathrm{C} 6$ \\
\hline Fresh air inlet 1 (m/s) & 6.6612 & 6.6612 & 0.0000 & 6.6612 & 0.0000 & 6.6612 \\
\hline Fresh air inlet $2(\mathrm{~m} / \mathrm{s})$ & 6.6612 & 6.6612 & 0.0000 & 6.6612 & 0.0000 & 6.6612 \\
\hline Fresh air inlet $3(\mathrm{~m} / \mathrm{s})$ & 6.6612 & 6.6612 & 0.0000 & 6.6612 & 0.0000 & 6.6612 \\
\hline Fresh air inlet $4(\mathrm{~m} / \mathrm{s})$ & 6.6612 & 6.6612 & 0.0000 & 6.6612 & 6.6612 & 6.6612 \\
\hline Suction $1(\mathrm{~m} / \mathrm{s})$ & 10.4287 & 0.0000 & 10.4287 & 15.4302 & 10.4287 & 5.4451 \\
\hline Suction 2 (m/s) & 4.2128 & 0.0000 & 4.2128 & 15.4302 & 4.2128 & 5.4451 \\
\hline Suction 3 (m/s) & 7.1390 & 0.0000 & 7.1390 & 15.4302 & 7.1390 & 5.4451 \\
\hline New suction (m/s) & 0.0000 & 0.0000 & 0.0000 & 0.0000 & 0.0000 & 5.4451 \\
\hline $\mathrm{High} \mathrm{H}_{2} \mathrm{~S}$ inlet $(\mathrm{m} / \mathrm{s})$ & 0.0068 & 0.0068 & 0.0068 & 0.0068 & 0.0068 & 0.0068 \\
\hline Low $\mathrm{H}_{2} \mathrm{~S}$ inlet $(\mathrm{m} / \mathrm{s})$ & $1.2257\left(10^{-5}\right)$ & $1.2257\left(10^{-5}\right)$ & $1.2257\left(10^{-5}\right)$ & $1.2257\left(10^{-5}\right)$ & $1.2257\left(10^{-5}\right)$ & $1.2257\left(10^{-5}\right)$ \\
\hline Outlet $1(\mathrm{~m} / \mathrm{s})$ & unspecified & unspecified & unspecified & unspecified & unspecified & unspecified \\
\hline Outlet $2(\mathrm{~m} / \mathrm{s})$ & unspecified & unspecified & unspecified & unspecified & unspecified & unspecified \\
\hline
\end{tabular}

For the baseline case, the velocity for the boundary conditions were determined from on-site measurements. Each suction outlet will have a different assigned velocity since friction loss, ducting leakages and other external factors were taken into consideration. Outlets 1 and 2 are designed to ventilate the surge chamber air space via the Main Access Tunnel (MAT). The ventilation boundary leaving the MAT was assigned to be at atmospheric pressure and the outlet velocities are calculated accordingly. For scenario $\mathrm{C} 2$, all three suction outlet velocities were set to zero to represent a condition where fresh air is allowed to be drawn into the computational domain from the access windows (reverse flow). This flow condition was used to ascertain the corresponding $\mathrm{H}_{2} \mathrm{~S}$ concentration response within the surge chamber air space. In the case of C3, the fresh air supply was shut-off and the air space was allowed to respond to the current suction design capabilities. The introduction of additional suction capabilities was investigated in C4. For C5, the fresh air inlet No. 4, located at the end of the chamber was the only inlet allowed to supply fresh air into the chamber. An increase in suction capabilities as expected by introducing an additional ventilation suction (similar dimensions as the existing suctions) were explored for the C6 case. Figure 4 shows the location of the additional suction introduced in the computing domain.

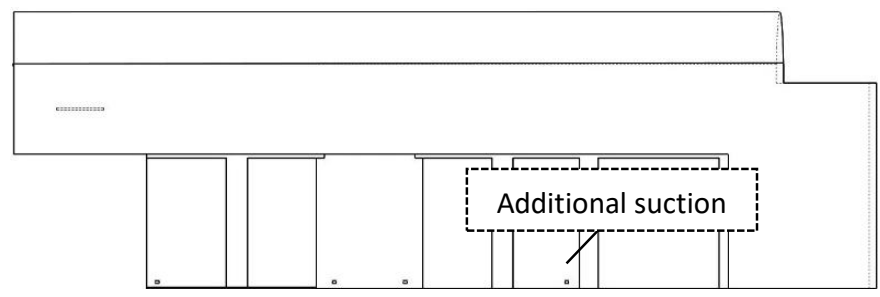

Fig. 4. Location of an additional suction in surge chamber 
Contrary to the baseline case, each suction outlet in the $\mathrm{C} 6$ case, including the additional suction outlet, was assigned similar velocity values (the total flowrate from all the outlets correspond to the baseline case).

\section{Grid Sensitivity Test and Validation}

One of the first checks in any numerical analysis is the reliability of the elements (grids) used to build the simulation model. To test the sensitivity of the computing domain to the grid resolution in the CFD model, the baseline case simulation was executed repeatedly whilst increasing refinement of the grid system after each simulation. Grid independence, which represents the stability of the numerical result, was achieved at 1.7 million elements in the current work. Subsequently, a validation exercise was carried out against the measured $\mathrm{H}_{2} \mathrm{~S}$ concentrations at several locations in the surge chamber. Figure 5 shows the locations within the chamber where the $\mathrm{H}_{2} \mathrm{~S}$ measurements were taken and the corresponding validation results can be found in Table 2 . The concentration measurements were made during the generation mode, as it represents the surge event, and is also when the highest amount of $\mathrm{H}_{2} \mathrm{~S}$ is expected within the surge chamber. The reliability of the CFD model, based on the validation outcome, was found to be good as the predicted and actual measurements varied by less than $10 \%$.

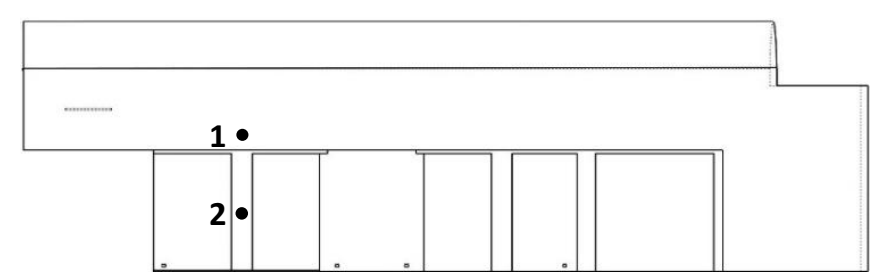

Fig. 5. Location of an additional suction in surge chamber

Table 2
Comparison in the results from the measurement and numerical
works
\begin{tabular}{llll} 
& & \\
Points of & Concentration of $\mathrm{H}_{2} \mathrm{~S}(\mathrm{ppm})$ & Percentage \\
measurement & Measurement & Numerical & difference (\%) \\
\hline 1 & 5.74 & 5.45 & 6.62 \\
2 & 6.72 & 6.62 & 1.49 \\
\hline
\end{tabular}

\section{Results and Discussion}

Figure 6 to Figure 8 illustrate the CFD simulation results with regard to the response of $\mathrm{H}_{2} \mathrm{~S}$ concentration and air flow velocities to the baseline and scenario cases in the current study. The midcross section illustration of the air flow and $\mathrm{H}_{2} \mathrm{~S}$ concentrations in Figure 8 provides a representation of the bulk conditions in the surge chamber and is referenced for all the cases in this study. A more elaborative discussion on the respective cases scenarios is presented in the subsequent sections. 


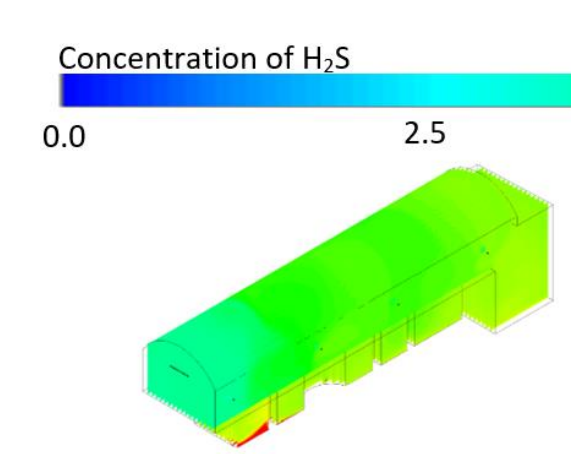

(a)

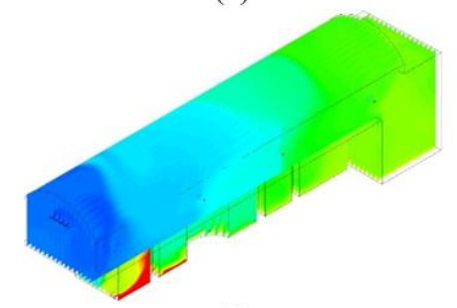

(d)

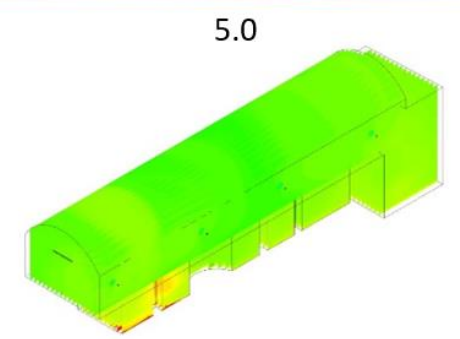

(b)

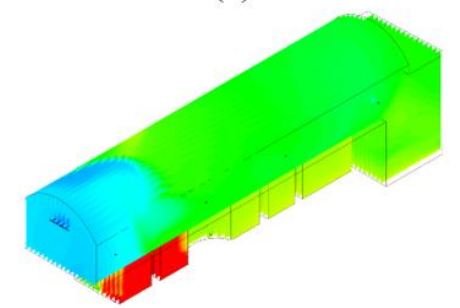

(e)

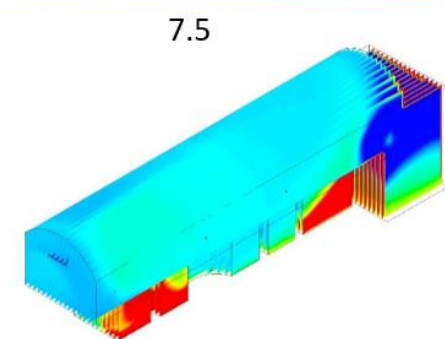

(c)

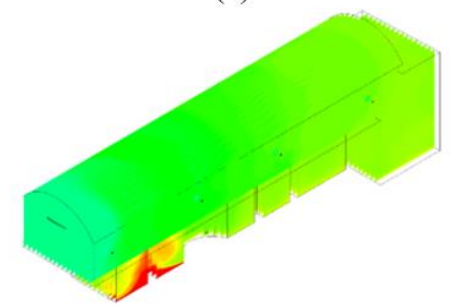

(f)

Fig. 6. The predicted $\mathrm{H}_{2} \mathrm{~S}$ concentration for different flow control conditions including (a) baseline, (b) $\mathrm{C2}$, (c) $\mathrm{C} 3$, (d) $\mathrm{C} 4$, (e) $\mathrm{C} 5$ and (f) $\mathrm{C} 6$

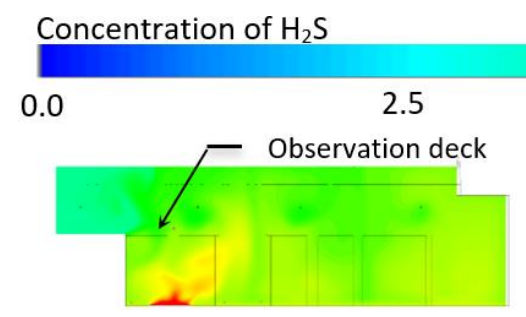

(a)

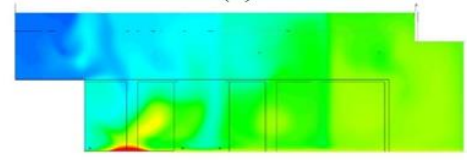

(d)

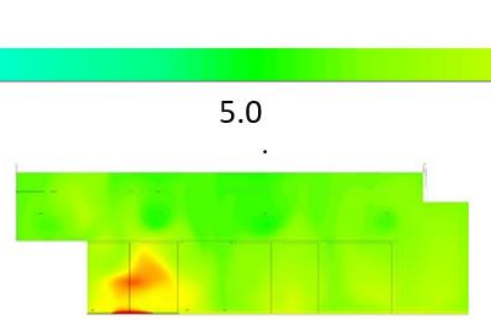

(b)

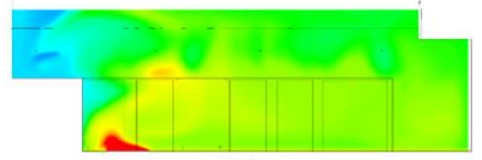

(e)

Parts per million (ppm)

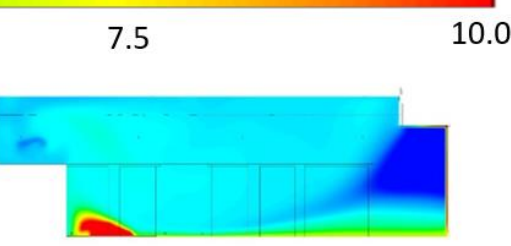

(c)

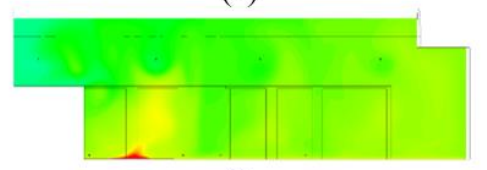

(f)

Fig. 7. The predicted $\mathrm{H}_{2} \mathrm{~S}$ concentration in the mid-cross section of surge chamber for different flow control conditions including (a) baseline, (b) C2, (c) C3, (d) C4, (e) C5 and (f) C6

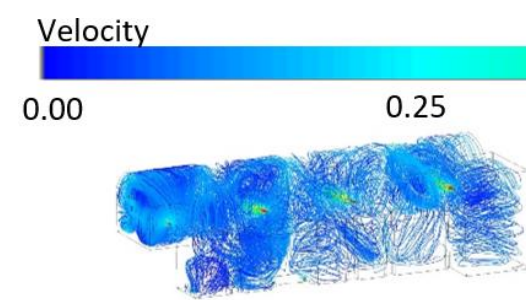

(a)

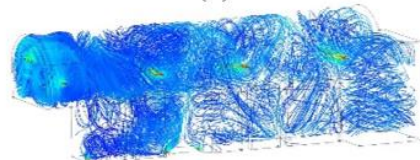

(d)

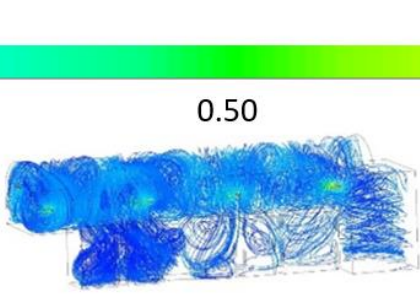

(b)

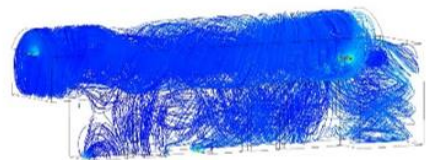

(e)

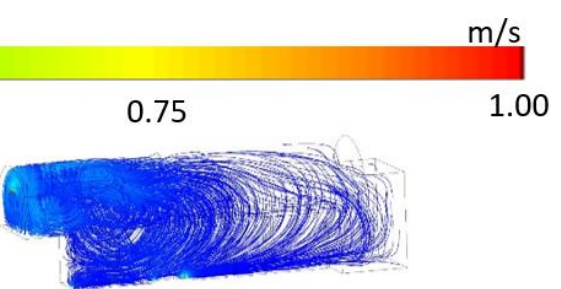

(c)

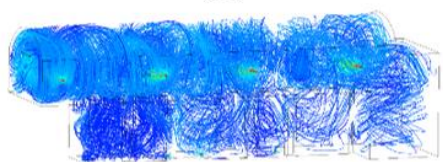

(f)

Fig. 8. The predicted velocity streamline for different flow control conditions including (a) baseline, (b) $\mathrm{C} 2$, (c) $\mathrm{C} 3$, (d) $\mathrm{C} 4$, (e) $\mathrm{C} 5$ and (f) $\mathrm{C} 6$ 


\subsection{The Baseline Case}

The baseline case represents the current air control design and ventilation performance within the surge chamber. The $\mathrm{H}_{2} \mathrm{~S}$ concentrations which are expected to stay above the water level after degassing is seen to migrate vertically towards the observation deck. The upward movements are believed to be associated to forced drafts from the fresh air intake. The hydrodynamic activity is also seen in the velocity streamline images captured in Figure 8(a) where intense mixing, in combination with a downdraft air flow pattern uplifts the $\mathrm{H}_{2} \mathrm{~S}$ concentrations (shown as a cross section in Figure 9).

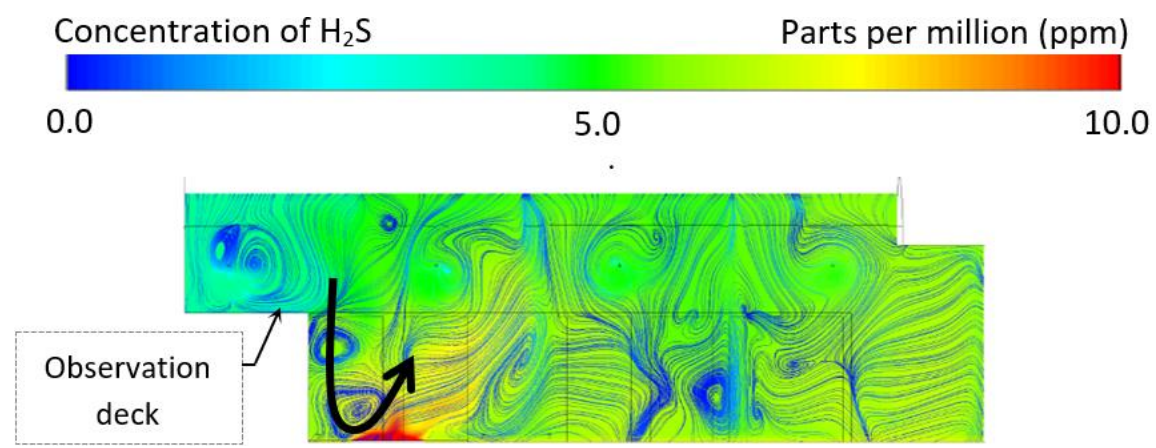

Fig. 9. Migration of $\mathrm{H}_{2} \mathrm{~S}$ towards the observation deck in the baseline case

The outcome of the baseline case simulation finds that the current ventilation system performance allows the $\mathrm{H}_{2} \mathrm{~S}$ to occupy a large section of the chamber starting from the water level where the degassing of $\mathrm{H}_{2} \mathrm{~S}$ is believed to occur. The suction located just above the water level is insufficient to manage the $\mathrm{H}_{2} \mathrm{~S}$ released from the water during turbulent conditions. Referring to Figure $7(\mathrm{a})$, the region on the right hand side of surge chamber shows significant amounts of $\mathrm{H}_{2} \mathrm{~S}$ despite the lower tendencies of $\mathrm{H}_{2} \mathrm{~S}$ degassing associated the calm water conditions. One explanation to the situation is found in the formation of vortices in the region as seen in Figure 8(a). The air from fresh air Inlet - 4 located on the right hand side of the chamber is responsible for the induced vortices in the air movements. Since all suction outlets are located on the left hand side of the chamber, most of the incoming air from fresh air Inlets - 1 to 3 flows preferentially into these outlets, leaving a portion of the fresh air volume to work its way into the space at the right hand side of the chamber. The observation is justified by the in-situ measurement taken during the generation mode whereby the velocities at the fresh air and suction outlets were found to be $26.6 \mathrm{~m} / \mathrm{s}$ and $21.8 \mathrm{~m} / \mathrm{s}$ respectively. A mass balance on the spatial air exchange would suggest that there is excess air which will remain in the surge chamber during steady state condition. This coincides with the simulation findings of air movement which influence the presence of $\mathrm{H}_{2} \mathrm{~S}$ in the identified air space.

\subsection{C2 - Suction Fans Off}

The impact of the surge chamber suction fans on the air space management was studied in the $\mathrm{C} 2$ case scenario. Figure $6(\mathrm{~b})$ and Figure 7(b) illustrate the location and tendencies of the air- $\mathrm{H}_{2} \mathrm{~S}$ concentration response if the suction fans are not in operation. The generation mode, as expected, increases the $\mathrm{H}_{2} \mathrm{~S}$ presence and subsequent migration to the surrounding air space. The simulation finds $11 \%$ higher concentration of $\mathrm{H}_{2} \mathrm{~S}$ in the area close to the observation deck as compared to the baseline. The response when the suction fans are not in operation suggest the importance of the negative pressure close to the water level in controlling the migration of $\mathrm{H}_{2} \mathrm{~S}$ to the higher elevations 
in the surge chamber. Table 3 summarizes the air quality for two points at different elevations from the reservoir water line.

\section{Table 3}

Comparison in the numerical results from the baseline and $\mathrm{C} 2$ cases

\begin{tabular}{llll}
\hline Points of & \multicolumn{2}{l}{ Concentration of $\mathrm{H}_{2} \mathrm{~S}(\mathrm{ppm})$} & $\begin{array}{l}\text { Percentage } \\
\text { measurement }\end{array}$ \\
Baseline & $\mathrm{C} 2$ & 10.64 \\
\hline 1 & 5.45 & 6.03 & 25.98 \\
\hline
\end{tabular}

\subsection{C3-Absence of Fresh Air Supply}

The absence of the inlet fresh air supply for the $\mathrm{C} 3$ case scenario has significantly reduced the concentration of $\mathrm{H}_{2} \mathrm{~S}$ within the chamber as shown in Figure $6(\mathrm{c})$ and Figure $7(\mathrm{c})$. The air space flow response to the pressure difference created between the higher and lower levels of the surge chamber, as a result of shutting-off the air supply from fresh air Inlets - 1 to 4, as shown in Figure 8(c). Outlets 1 and 2, which were designed to be ventilation outlets, experience a reverse flow phenomenon and allows outside air to flow into the surge chamber, suppressing $\mathrm{H}_{2} \mathrm{~S}$ concentrations above the water surface. Due to the large volume of air entering the chamber, majority of the area above the water level is filled with fresh air after steady state condition are achieved.

\subsection{C4 - Enhanced Suction Capabilities}

In the C4 scenario where higher suction flow rates were assigned to the suction outlets, a significant drop in $\mathrm{H}_{2} \mathrm{~S}$ concentration above the water level was observed. As shown in Figure 6(d) and Figure $7(\mathrm{~d})$, the almost doubled suction velocity at $46 \mathrm{~m} / \mathrm{s}$ compared to the design capacity of 27 $\mathrm{m} / \mathrm{s}$, removed enough air volume to create a circulation of fresh air from the outside to enter the chamber and contained the spread of $\mathrm{H}_{2} \mathrm{~S}$ to other areas. As compared to the $\mathrm{C} 3$ scenario, the containment of $\mathrm{H}_{2} \mathrm{~S}$ is focused on the areas closest to the vents and not as extensive as the latter. The advantage of the $\mathrm{C} 4$ scenario is the overall reduction of $\mathrm{H}_{2} \mathrm{~S}$ which is removed through the vents and not merely a suppression activity from the entry of large amounts of outside air.

\subsection{C5 - Only Fresh Air Inlet 4 Is Operating (Fresh Air Supply Reduction)}

The function of the fresh air inlets is to reduce the $\mathrm{H}_{2} \mathrm{~S}$ concentration via an air mixing strategy. However, air flow into the chamber turned out to have a negative impact on the overall air movement and led to the migration of $\mathrm{H}_{2} \mathrm{~S}$ to the higher chamber elevations as seen in the baseline and $\mathrm{C} 2$ scenarios. To further explore the effects of fresh air supply to the chamber, a scenario whereby smaller amounts of fresh air was introduced at locations which were farther from air outlets 1 and 2 was simulated as case $\mathrm{C} 5$. Figure 6(e) and Figure 7(e) show the predicted $\mathrm{H}_{2} \mathrm{~S}$ concentration in the chamber when only fresh air inlet 4 was allowed to operate. Compared to the baseline and C2 cases, more fresh air is seen to have entered the chamber via air outlets 1 and 2 . The concentration of $\mathrm{H}_{2} \mathrm{~S}$ is also much lower and had not migrated vertically to the observation deck area. The observation in C5 further strengthens the understanding of the air flow movements and direction in the chamber and how it influences the spread of $\mathrm{H}_{2} \mathrm{~S}$ in the air space considered in the study. 


\subsection{C6 - Additional Suction Ducting}

The addition of a suction outlet close to the reservoir water level was explored in the $\mathrm{C} 6$ scenario. The observation from Figure 6(f) and Figure 7(f), suggests a very small drop in the $\mathrm{H}_{2} \mathrm{~S}$ concentrations at the area close to the outlets. Based on the predicted $\mathrm{H}_{2} \mathrm{~S}$ reading at point 1 , the percentage difference of the $\mathrm{H}_{2} \mathrm{~S}$ concentration compared to the baseline is only $5 \%$. The additional suction impact was too small to cause any changes to the air flow movement and therefore did not drive a major contribution to the overall condition of the chamber air space. There was minimal migration of $\mathrm{H}_{2} \mathrm{~S}$ in the vertical direction and was not as significant as the baseline and $\mathrm{C} 2$ cases.

A comparison of all the case scenarios, based on the $\mathrm{H}_{2} \mathrm{~S}$ concentrations at points 1 and 2 in parts per million (ppm), was explored in the study and is shown in Figure 10. As expected, the C3 and C4 scenarios provided the best solutions for the optimized air space management in the surge chamber. In Figure 10 as well, a red line representing the exposure limits of $\mathrm{H}_{2} \mathrm{~S}$ as suggested by the American Conference of Governmental Industrial Hygienists (ACGIH) is shown to provide reference to the modelled operating conditions [19]. The 15-minute Short-Term Exposure Limit (STEL) for $\mathrm{H}_{2} \mathrm{~S}$ suggested by ACGIH is 5 ppm.

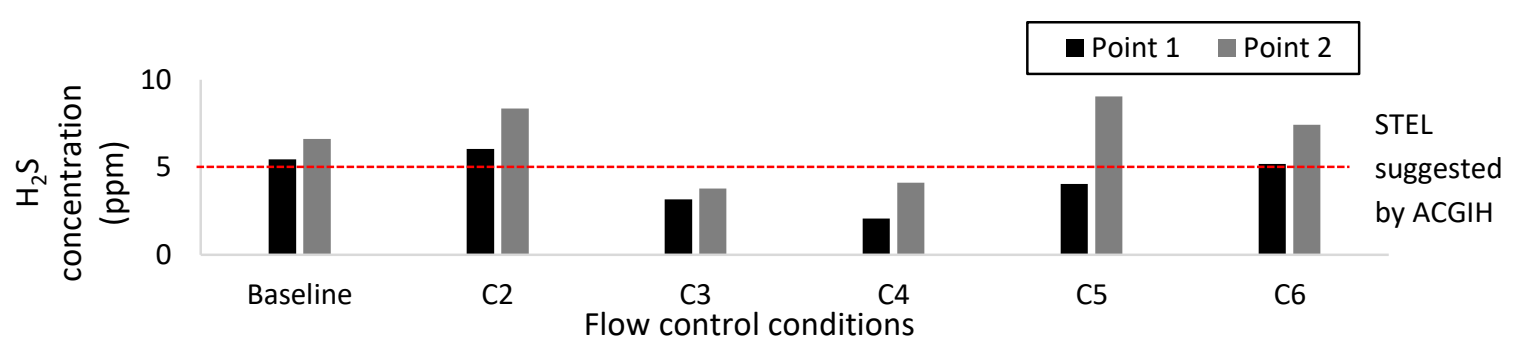

Fig. 10. The graph of $\mathrm{H}_{2} \mathrm{~S}$ concentration versus flow control conditions

From Figure 10, there are three scenarios where the concentration of $\mathrm{H}_{2} \mathrm{~S}$ at point 1 (one meter above the observation deck) is higher than the suggested 15-minute STEL. The C2 scenario is predicted to have the highest concentration of $\mathrm{H}_{2} \mathrm{~S}$ at the measured location of point 1 (6.02 ppm).

\section{Conclusions}

The numerical model of the hydropower plant surge chamber was helpful in providing an understanding of the flow conditions in relation to the management of $\mathrm{H}_{2} \mathrm{~S}$ concentrations. The validated CFD model provided the following insights from the operating case scenarios based on the boundary conditions assigned to the computational domain:

i. The current suction flow rate in the surge chamber (baseline) is insufficient in removing the $\mathrm{H}_{2} \mathrm{~S}$ released from the water.

ii. An inappropriate location of the fresh air inlet can influence flow movements in the chamber air space and, as observed in this study, may cause the migration of $\mathrm{H}_{2} \mathrm{~S}$ to higher chamber elevations.

iii. Removing or reducing the fresh air supply increases the pressure difference between the surge chamber and the ambient, allowing more fresh air to enter the chamber. The air movement as a result of a significant increase of outside airflow into the chamber acts to suppress $\mathrm{H}_{2} \mathrm{~S}$ concentrations adjacent to the water surface.

iv. Additional suction fans have insignificant influence in managing $\mathrm{H}_{2} \mathrm{~S}$ concentrations in the surge chamber. Nonetheless, a combination of higher outside airflow entering the chamber and an effective suction system will result in an optimized air space management. 


\section{Acknowledgement}

This research was funded by a research and development (R\&D) grant from Tenaga Nasional Berhad (grant number: R-G-RD-0351-19-015-1).

\section{References}

[1] Guo, Qiang, Jianxu Zhou, Yongfa Li, Xiaolin Guan, Daohua Liu, and Jian Zhang. "Fluid-structure interaction response of a water conveyance system with a surge chamber during water hammer." Water 12, no. 4 (2020): 1025. https://doi.org/10.3390/w12041025

[2] Braun, Martin, Courtney S. Coleman, and Donald A. Drew, eds. Differential equation models. Vol. 1. Springer-Verlag, 1983. https://doi.org/10.1007/978-1-4612-5427-0

[3] Trisugiwo, M., H. Zabidi, and F. Ahmad. "Joint analysis to evaluate geological over-break in excavation of surge chamber cavern." Procedia Chemistry 19 (2016): 751-756. https://doi.org/10.1016/i.proche.2016.03.080

[4] Yassine, Omar, Osama Shekhah, Ayalew H. Assen, Youssef Belmabkhout, Khaled N. Salama, and Mohamed Eddaoudi. "H2S sensors: fumarate-based fcu-MOF thin film grown on a capacitive interdigitated electrode." Angewandte Chemie 128, no. 51 (2016): 16111-16115. https://doi.org/10.1002/ange.201608780

[5] Sabodin, Nurushshahirah, and Adekunle Qudus Adeleke. "The Influence of Government Regulation on Waste Reduction Among Kuantan Malaysian Construction Industry." Journal of Advanced Research in Applied Sciences and Engineering Technology 10, no. 1 (2018): 72-76.

[6] Sander, Rolf. "Compilation of Henry's law constants (version 4.0) for water as solvent." Atmospheric Chemistry and Physics 15, no. 8 (2015): 4399-4981. https://doi.org/10.5194/acp-15-4399-2015

[7] Zhu, Pengen, Weizhi Wei, Jian Mei, Jiangfeng Tu, and Ru Ding. "Numerical Simulation \& Scene Experiment of Metro Tunnel with Crossover Interval under Fire Conditions." Procedia Engineering 205 (2017): 87-94. https://doi.org/10.1016/i.proeng.2017.09.938

[8] Yang, Weixiao, Jincheng Xing, Jianxing Li, Jihong Ling, Haixian Hao, and Zhiqiang Yan. "Impacts of opening baffle of city road tunnels on natural ventilation performance." Frontiers of Structural and Civil Engineering 7, no. 1 (2013): 55-61. https://doi.org/10.1007/s11709-013-0194-x

[9] Porras-Amores, César, Fernando R. Mazarrón, Ignacio Cañas, and Paola Villoría Sáez. "Natural ventilation analysis in an underground construction: CFD simulation and experimental validation." Tunnelling and Underground Space Technology 90 (2019): 162-173. https://doi.org/10.1016/i.tust.2019.04.023

[10] Diego, Isidro, Susana Torno, Javier Toraño, Mario Menéndez, and Malcolm Gent. "A practical use of CFD for ventilation of underground works." Tunnelling and Underground Space Technology 26, no. 1 (2011): 189-200. https://doi.org/10.1016/i.tust.2010.08.002

[11] Ji, Jie, Z. H. Gao, C. G. Fan, W. Zhong, and J. H. Sun. "A study of the effect of plug-holing and boundary layer separation on natural ventilation with vertical shaft in urban road tunnel fires." International Journal of Heat and Mass Transfer 55, no. 21-22 (2012): 6032-6041. https://doi.org/10.1016/j.ijheatmasstransfer.2012.06.014

[12] Parra, M. T., J. M. Villafruela, F. Castro, and C. Mendez. "Numerical and experimental analysis of different ventilation systems in deep mines." Building and Environment 41, no. 2 (2006): 87-93. https://doi.org/10.1016/j.buildenv.2005.01.002

[13] Mukhtar, Azfarizal, Khai Ching Ng, and Mohd Zamri Yusoff. "Design optimization for ventilation shafts of naturallyventilated underground shelters for improvement of ventilation rate and thermal comfort." Renewable Energy 115 (2018): 183-198. https://doi.org/10.1016/i.renene.2017.08.051

[14] Stefopoulos, E. K., and D. G. Damigos. "Design of emergency ventilation system for an underground storage facility." Tunnelling and Underground Space Technology 22, no. 3 (2007): 293-302. https://doi.org/10.1016/i.tust.2006.07.002

[15] Ho, J. C., H. Xue, and K. L. Tay. "A field study on determination of carbon monoxide level and thermal environment in an underground car park." Building and Environment 39, no. 1 (2004): 67-75. https://doi.org/10.1016/j.buildenv.2003.07.006

[16] Kumar, Nikhil, Tetsu Kubota, Yoshihide Tominaga, Mohammadreza Shirzadi, and Ronita Bardhan. "CFD simulations of wind-induced ventilation in apartment buildings with vertical voids: Effects of pilotis and wind fin on ventilation performance." Building and Environment 194 (2021): 107666. https://doi.org/10.1016/i.buildenv.2021.107666

[17] Menter, Florian R. "Two-equation eddy-viscosity turbulence models for engineering applications." AIAA Journal 32, no. 8 (1994): 1598-1605. https://doi.org/10.2514/3.12149

[18] Menter, Florian R. "Review of the shear-stress transport turbulence model experience from an industrial perspective." International Journal of Computational Fluid Dynamics 23, no. 4 (2009): 305-316. https://doi.org/10.1080/10618560902773387 
[19] Fabian-Wheeler, Eileen E., Michael L. Hile, Dennis Murphy, Davis E. Hill, Robert J. Meinen, Robin C. Brandt, Hershel A. Elliott, and Daniel Hofstetter. "Operator exposure to hydrogen sulfide from dairy manure storages containing gypsum bedding." Journal of Agricultural Safety and Health 23, no. 1 (2017): 9-22. https://doi.org/10.13031/jash.11563 